\title{
Research on Mental Health Education of Children in Two-child Family
}

\author{
Haibo He \\ Ningbo Institute of Education, China
}

Keywords: Two-child family, child psychology, mental health, education.

\begin{abstract}
With the deepening reform of early childhood education, the teaching level of early childhood education has risen to a new historical height. After the liberalization of the "two-child" policy in China, the number of two-child families has increased. The mental health education of the young children in two-child family is of great significance to society, families and young children themselves. This paper takes the psychological representation of the two-child family as the entry point, analyzes and summarizes the main mental health problems of the children of the two-child family as lack of security, behavioral disorder, and lack of principle.
\end{abstract}

\section{Introduction}

The mental health of young children refers to the good psychological state of emotion and socialization after their reasonable needs and wishes are met. The good psychological state is mainly manifested as: the child is satisfied with himself, the emotion is lively and happy, can adapt to the surrounding environment, the relationship is friendly and harmonious, and the individual's intelligence is fully exerted and exerted [1]. The psychology of early childhood is the key to the formation of the child's character. The pros and cons of the child's personality characteristics directly affect the child's healthy growth in the future and the attitude toward the future.

The Fifth Plenary Session of the 18th CPC Central Committee, which was closed on October 29, 2015, decided to adhere to the basic national policy of family planning, improve the population development strategy, fully implement the policy of a couple of children to have two children, and actively carry out the action against population aging [1]. "Completely liberalizing the two-child policy" means that couples with suitable conditions have the potential to have two children, and families with non-only children will increase. This means that more children will assume the role of non-only children, and the two children facing the family. The environment, whether it is a long-term child or a young child, will encounter stumbling blocks in the path of mental health. The psychological self-regulation ability of young children is weak [1]. Therefore, the mental health education of children in two-child families is particularly important. The author will take the real case from the side as the entry point, analyze and summarize the causes and solutions of the main mental health problems of the children of the second child.

\section{Common psychological problems and causes of children in two children's families}

We conducted a parent survey in 226 second-child families at the school and found that the psychological problems of children in the second-child family are often the following: Possession of possessiveness becomes stronger: Some children are not so sticky to their parents when they are only children. But after adding a younger brother or sister to their home, they begin to stick to their parents. Especially when I saw that my parents focused on caring for their younger siblings, they were very uncomfortable [2]. They often clashed with their younger siblings for food, competition, and toys.

Irritable and irritable: Some children have been very embarrassed at home, and they are obedient. Never provoke a bad life [3]. There was an abnormality in the behavior of the second child in the family. The main manifestation was that it was mischievous and irritating in school, often fighting and fighting, and sometimes falling from time to time.

Sensitive: Some children are unhappy after hearing that their father and mother are praised after they are born [2]. They are always happy when they are not at home, or take away the food in their 
younger brother's mouth, or deliberately have fun with their younger siblings. The toy grabbed and threw it on the ground.

Why are the psychological problems of the second-born family vulnerable to these problems? It turns out that the only child is used to everyone, and there is no sharing habit and ability [1]. Once the parents put too much energy into the second child, ignoring the concern for the boss, the boss will have the feeling of being abandoned, they will push the responsibility of parents no longer love themselves to the younger brother. Children can't use language to express this feeling of "out of favor" and can only show their behavior.

\section{The significance of mental health education for children in two-child family}

\subsection{Resolve conflicts and maintain the stability and harmony of the family and society.}

Long before the introduction of this policy, many families have given birth to "two treasures" for various reasons, but unpleasant and even unfortunate things have happened [3]. These things have affected the stability and harmony of the family and society. It is urgent to strengthen the mental health education of young children to resolve conflicts and avoid the recurrence of future tragedies.

\subsection{Give children a good living environment.}

A good living environment includes a physiological environment and a psychological environment. Early childhood mental health education can avoid many unnecessary contradictions, reduce the situation of children's grievances, and lay a good foundation for the healthy growth of children [2]. Do a good job in mental health education for long-term children, and accept the "two treasures" in a happy manner, while helping young children to stabilize their health and mental health. Do a good job in mental health education for young children. It is easier for long-term children to get along with them, and be warm and friendly.

\subsection{Promote the social development of young children.}

Before the children step into the society, the family is the main place for them to try to interact, especially for the two-child family [3]. Appropriate mental health education can help children to sort out their emotions, establish a sound personality, etc. In the process of harmonious coexistence with brothers and sisters, cultivate good quality of sharing, cooperation and mutual assistance, which is very beneficial to the social development of young children [4]. When children can handle the problems of dealing with their brothers and sisters, they can push others and make inferences. After they leave the family, their social development will be smoother.

\section{Child mental health standard}

Childhood is a crucial period for the formation of a person's personality, personality, thoughts and behaviors, values, and moral concepts. Children with mental health tend to develop better physically and mentally, and are more able to adapt to the surrounding environment.

\subsection{Positive emotions.}

Maintaining continuous happiness and positive mood is the first child's mental health standard. Such emotions help to improve the efficiency of activities, and are often praised and praised by parents and neighbors, while positive emotions are strengthened and children enter a virtuous circle. Children also have joy, anger, sadness, and happiness [4]. Healthy children also have short-term negative emotions, but negative emotions are too excessive and too frequent. If emotions such as anxiety, fear, coercion, depression, etc. appear repeatedly, it is difficult to claim It is mental health.

\subsection{The intelligence is normal.}

Incorporating intelligence into children's mental health standards is mainly due to the child's IQ and the ability to adapt to society. Children with normal intelligence have independent, original, astute and energetic personality traits that can quickly adapt to the surrounding environment [4]. 
Children with low mentality have poor social adaptability, and often cannot adapt to the collective life and learning of kindergartens. They are psychologically stressed and prone to various psychological problems of children and require special education and nursing.

\subsection{Personality.}

The third aspect of children's mental health standards is to examine the child's personality and self-awareness. Personality is the most essential expression of human personality, and self-consciousness plays a key role in the formation of personality. Mentally healthy children are relatively stable, cheerful, enthusiastic, generous, and brave [5]. In self-awareness, I began to correctly understand and evaluate myself. Self-esteem is developing, seeking independence, and full of confidence in myself. The unhealthy children's character develops poorly, showing timidity, indifference, loneliness, inferiority, and lack of self-respect.

\subsection{Ability to interact with people.}

Children's mental health standards are also reflected in the harmony of interpersonal relationships commensurate with the child's social range. Children's interpersonal relationship mainly refers to their relationship with parents, teachers and peers. From these interpersonal relationships, children's mental health status can be reflected [6]. Mentally healthy children are willing to interact with others, be good at cooperating and sharing with their peers, understand and respect others, be generous and friendly, and be easily understood and accepted by others [6]. A child with unhealthy mentality cannot cooperate with others, is indifferent to people, lacks compassion, has suspicion, jealousy, withdrawal, and cannot be placed in the collective, and is incompatible with the person.

\subsection{The integrity of the will and the coordination of behavior.}

The final aspect of children's mental health standards is to examine the health and coordination of the individual's will and behavior in the daily life of the child.

Mentally healthy children have the germination of the will before the age of three, and can initially use their words to dominate their actions and the desire to act independently. After the age of 3, the consciousness, persistence and self-control in the quality of the will develop, but in general, development is limited [7]. However, children with imperfect will have poor tolerance, fear of difficulties, do things with two minds, lack of concentration, lack of self-control; inconsistency in behavioral performance, confusion in thinking, change in behavioral response, and temper for a little thing, or it is indifferent to strong stimuli.

\section{Method for improving the mental health problem of children in two children family}

Parents are the first teachers of children, and their physical and mental development has its own unique characteristics and laws. Early family education has many influencing factors on children's mental health. Among them, family education mentality and family education have a great influence on children's mental health, which will be discussed in detail below.

\subsection{The impact of family education mentality on children's psychology.}

The influence of family education mentality on children's psychology is one of the factors influencing the mental health of early childhood education. Psychology believes that the formation of personal psychological quality is critical depends on the education and influence of parents in childhood. The main body of parental family education plays a decisive role in the early family [8]. A bad educational mentality will inevitably lead to bad educational behavior. Therefore, parents should maintain a good educational mentality in early childhood family education mentality, so that they can form a good educational behavior under psychological control and promote the benign development of children's psychology.

\subsection{The impact of family education on children's psychology.}

The influence of family education on children's psychology is another influential factor of early 
family education on children's mental health. The method of family education refers to the methods and forms commonly used by parents in the activities of raising and educating children. It is a generalization of the characteristics of parents' various parenting behaviors and is a behavior style with relative stability. In the early family education, the influence of family education on children's psychology is mainly reflected in the influence of children's personality [8]. The family education method directly affects the formation of children's good personality. American social psychologist and personality psychologist all port believes that personality is the dynamic organization of the internal and mental system of the individual that determines the unique behavior and thinking of the person. Parkinson regards the family as a "manufacturing factory that directly affects the formation of a good character for children.” Therefore, it is necessary to explore strategies for early family education to promote children's mental health.

\subsection{Creating a harmonious emotional atmosphere.}

Young children are good at imitating. They learn how to love people from adults. Adults have the responsibility to create a harmonious emotional atmosphere for them to promote the healthy development of children's psychology [5]. The "Guide" pointed out that "the creation of a warm interpersonal environment can fully feel the affection and care, positive and stable emotional emotion". Children living in the family, school, society and other environment, the family's loving and supportive husband and wife relationship, the easy and equal teacher-child relationship in the kindergarten, and the socially friendly and mutually beneficial people's relationship can make the children feel love, enjoy being loved, and learn. Caring love for thus gaining is a sense of security and developing sociality. Love and respect are mutual. How can children with subtle influences in a warm psychological environment have serious inferiority or sensitive behavior?

\subsection{Establish a correct role orientation.}

People play a variety of roles in society, and correctly understanding the meaning of different roles is a good start for the role of the task. But young children still have no ability to grasp the meaning of different roles, and they have no ability to freely adapt and adapt to different roles [3]. They need help and guidance. For long-term children, you should inform your younger siblings in advance, and experience the role of your brother and sister in the way of "Doll House" and other games, and give them time and method to transition and adapt. After the "two treasures", let the long-term children participate in the maintenance, experience a sense of responsibility and mission, learn to grow up well while caring for their younger siblings, become their role models, learn to share, but also harvest the love of younger siblings [4]. The "Outline" pointed out: "Children are not passive "protected persons." For young children, they should be given sufficient opportunities to develop autonomy and exert their own value, so that he can experience independence and enhance self-confidence. "Big baby" is not selfish, "two treasures" do not depend on, and they are happy.

\subsection{Establish equal rules for getting along.}

Children are young, but their eyes are bright and sensitive. Before they establish their own rules of life, they can find out the principles of adults from the usual bits and pieces. The "unfair" rule has a negative impact on the principled awareness of young children. The typical thinking, such as "You are a brother, first apologizing to the younger brother", is harmful to the child's correct right and wrong. The principle of fairness such as "doing things wrong with people" should be established. Long children follow the rules and will voluntarily set an example instead of retreating without principle. If young children accept the rules, they can understand right and wrong, and they will not be unscrupulous [6]. There are fixed universal rules in kindergartens and public places. Everyone is equal before the rules, and no special cases are allowed due to age. The rules of equality are an important way to help young children build a sense of principle.

\subsection{Be good at using incentives and other means to cultivate good character for young children.}

Enthusiasm is an important condition for a successful career. Children are born, but they are extremely vulnerable and can be easily bruised and destroyed by blows and failures. Therefore, 
teachers should pay great attention to protecting and stimulating the enthusiasm of young children, and must not "splash cold water." Our Normal University kindergartens hold "Art Festivals" every year to create opportunities for children to demonstrate their abilities [7]. Each class has a "small stage", so that every child can go on stage to perform programs for the whole class, win plaudits, cultivate their guts to form a healthy mind; hold a "small art exhibition", each child has a work to show and cultivate Self-confidence. Among them, the positive evaluation of teachers is very important, such as "You are doing really well", "You are very good at painting", "Your imagination is really rich" and other positive encouragement language, these encouraging words can make children as a child [6]. The beliefs are kept in mind, forming a positive health mentality of "I will do better, I am capable”. With this healthy state of mind, it has laid a solid foundation for children to grow up.

\subsection{Extend the effectiveness of heart education in family education.}

The family is the first school for the growth of young children, and it is an important place to cast children's good character and personality. The pros and cons of the family environment and parent education will have positive and negative effects on children's mental health. Therefore, teachers should pass on the importance of mental health education to parents through various channels, and obtain positive cooperation from the family, so that mental health education can synchronize with others and extend the effectiveness of mental health education. First, let parents pay attention to their mental health and let them understand that their mental health will affect their life [8]. At the same time, from the psychological point of view to help analyze the relationship between family education methods and children's mental health, remind parents to start from scratch, start from their own, and use their healthy words and deeds, personality to influence children. Second, let parents create a good family atmosphere for their children and help them form a good personality.

\section{Summary}

In short, early childhood is a critical period for a person's psychological development. Mental health education for children with two children is a long-term task. Paying attention to and strengthening children's mental health education is becoming the consensus of the whole society. The main factors for cultivating children to become excellent talents come from family education, school education, social education, etc. I have spent most of my life in the family since I was a child, so family education has become the cornerstone for nurturing children.

\section{Acknowledgement}

Foundation for Educational Science Planning Projects in Zhejiang Province (Project No.: 2018SCG115).

\section{References}

[1] X.M. Song, Psychological impact of the second child on the children and countermeasures, Education Guide, 2015, vol.6, pp.80-83.

[2] Zh.J. Wang, Research on the psychological problems of the only child, Changchun: Changchun University of Science and Technology, 2009, vol.3, pp.20-22.

[3] F.T. Fang, Hot issues and solutions for pupils' mental health education, New curriculum learning, 2014, vol.5, pp.12-13.

[4] J.P. Duan, Research and practice of mental health curriculum teaching, Knowledge Window, 2014, vol.7, 21-23.

[5] Y.F. Jiang, Analysis of children's mental health education, Youth years, 2011, vol.12, 53-56.

[6] X.Sh. Wang, on the countermeasures to strengthen children's mental health education, New curriculum research, 2007, vol.9, pp-43-44. 
[7] Sh.Y. Li, On the problems and countermeasures of children's mental health education, Journal of Kunming Teachers College, 2005, vol.2, pp.88-90.

[8] Q.T. Shen, Preliminary exploration of Children's mental health education, Journal of Ningbo University, 2002, vol.1, pp.57-59. 